\title{
Analyzing Pre-service Science Teachers' Physics Materials
}

\author{
Hasan Özcan ${ }^{*}$, Hakkı İlker Koştur² \\ 'Department of Mathematics and Science Education, Aksaray University, Faculty of Education, Aksaray, Turkey, ${ }^{2}$ Department of Primary Education, \\ Başkent University, Faculty of Education, Ankara, Turkey
}

*Corresponding Author: hozcan@aksaray.edu.tr

\section{ABSTRACT}

Recently, with the influence of science, technology, engineering, and mathematics education approach, the material design has become an important aspect within science courses. The material development course in science curriculums is a unique opportunity to evaluate pre-service teachers' material designs. In this study, student science teachers' physics materials were subjected to critiquing, while the authors discussed the advantages and disadvantages of their designs with a consideration of possible misconceptions. In the study, a content analysis technique, as one of the qualitative analysis methods was used. There were 27 materials and lesson plans in total, concerning the physics topics. The findings are presented under the titles of energy, light, sound, and electricity. Results showed that only three of the materials were linked to a misconception. Moreover, a fair amount of the participants chose to design either too simple, easy to build, easy to find, digital, or irrelevant teaching materials. This result can be recognized as a critical finding in this research and described as the unwillingness of the participant pre-service teachers. Findings are discussed with an effort to settle the misconceptions and the unwillingness of pre-service teachers.

KEY WORDS: physics materials; material design; misconception; unwillingness

\section{INTRODUCTION}

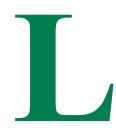

earning science is a process of construction and reconstruction of previously owned personal theories by continually refining existing knowledge and constructing concepts (Deslauriers et al., 2011; Martin, 2012). Sometimes, existing knowledge can cause a misunderstanding of new concepts. This misunderstanding has been named variously in different sources. In this study, the term "misconception" will be used.

Misconceptions are problematic issues for both students and teachers in science education (Knight, 2004; Yagbasan and Gülcicek, 2003; Weaver, 1965). Since science contains a vast number of abstract concepts, science courses are proned to various misconceptions. In addition, the constructivist approach suggests that students bring their already-existing knowledge, previous experiences, as well as their interpretations to the classroom (Deslauriers et al., 2011; Martin, 2012). This interaction produces difficulties in the process of teaching science concepts (Häussler and Hoffmann, 2000; McDermott et al., 2000; Yagbasan and Gülcicek, 2003).

Main stakeholders in the teaching process are teachers. Students compare their already existing knowledge with the teachers' knowledge and reconstruct their conceptual understanding. Student misconceptions should be revealed and addressed by teachers. On the other hand, where teachers themselves have misconceptions about the content they teach, conceptual development of students would be affected negatively (Akgun et al., 2005; Crawley and Arditzoglou, 1988; Stein et al., 2008; Tiberghien et al., 1998).
Recently, with the influence of science, technology, engineering, and mathematics (STEM) education approach, the material design has become an important aspect of some science courses. In the current Turkish science education curriculum, designing science products to solve daily life problems are the main objective of science, engineering, and entrepreneurship applications aspect (Ministry of National Education, 2018). Such goals about material design and the growing interest in STEM education approach brings out the question about the quality of teachers' own material designs. The material development course in science curriculums is a unique opportunity to evaluate pre-service science teachers' material designs. In this course, the main goal is to teach preservice teachers about various educational technologies and materials as learning tools, the characteristics of education materials, and the evaluation of educational materials.

In the following sections:

- The term "material" stands for the educational materials, which help students to facilitate new theoretical knowledge by hands-on trials. For example, while a human body model or an inclined ramp can be categorized as a material, worksheets, or written resources cannot.

- The term "designer" stands for the pre-service teacher who designed and presented the material that is being discussed.

- The term "experimenter" stands for the pre-service teacher who participated to try the material that is being presented by the designer of the material.

- The term "pre-service teacher" stands for the $3^{\text {rd }}$ grade preservice science teachers who attended the material design course and presented their lesson plans and materials. 
In this study, pre-service science teachers' physics materials were critiqued, while the advantages, disadvantages, and misconceptions in their designs were discussed by the authors. For a better understanding, of which grade levels and physical concepts were included in the study, middle-school science curriculum is introduced in the following section.

\section{Middle-school Science Curriculum}

Turkish students are involved in science courses from the $3^{\text {rd }}$ to $8^{\text {th }}$ grade. Primary school science courses begin in the $3^{\text {rd }}$ grade and continue in the $4^{\text {th }}$ grade. Middle-school science in $5^{\text {th }}, 6^{\text {th }}$, $7^{\text {th }}$, and $8^{\text {th }}$ grades is taught through an integrated curriculum. The main goal of Turkish science education has been scientific literacy since the 2005 science curriculum. The new approach in the current curriculum, however, is the engineering, design, and entrepreneurship concepts. Such concepts can be easily linked to the idea that the curriculum has been influenced of STEM education approach even though it is not mentioned in the curriculum. There are 302 learning outcomes in the curriculum of which 223 of them are taught in middle-school science courses. Among these 223 learning outcomes, 75 of them are physics outcomes, and named as physical phenomena subject, which is one of four main subjects of the program: (1) The Earth and the universe; (2) living creatures and life; (3) physical phenomena; and (4) nature of the matter. As misconceptions are the main focus of this study, the physics concepts to be taught in middle-school science courses are listed in Table 1. To view the topics easier, in the findings section, they are categorized as (a) energy; (b) light; (c) sound; and (d) electricity.

\section{REVIEW OF LITERATURE}

As Weaver (1965) indicated more than 50 years ago, "misconception" itself is a serious matter. In the pursuit of developing a scientifically literate citizenry (Stein et al., 2008), misconceptions have often been a focus of interest for researchers (e.g., Narjaikaew, 2013; Pejuan et al., 2012; Gönen, 2008; Kikas, 2004; Crawley and Arditzoglou, 1988; Lawrenz, 1986; Weaver, 1965).

Stein et al. (2008) administered "The Science Belief Test" on pre-service elementary teachers. In this test, 47 statements are about general science topics. Participants respond to statements as true or false, they are asked to provide explanations for their answers. The findings showed that their pre-service elementary teachers' correct response rates were $>60 \%$. More importantly to the present study, their participants possessed a significant number of misconceptions for the physical science concepts.

Crawley and Arditzoglou (1988) administered the "Physical Science Misconceptions Test" to 49 pre-service elementary teachers. This test has 41 multiple-choice questions about general science topics. Participants scored an average of 13.1 points out of 41 on the test. Crawley and Arditzoglou noted that their participants were unaware of the correct scientific explanations to many of the physical science concepts included on the test.

Kikas (2004) administered a science questionnaire to 198 trainees, primary and subject teachers. The questionnaire included questions about velocity/force, seasons, and changes of matter. Results showed that most of the misconceptions were about velocity/force topic.

Narjaikaew (2013) applied a two-level multiple-choice about the force and motion topic on 123 primary school teachers. Results showed that the participants had a low conceptual understanding on force and motion.

Gönen (2008) asked 267 science and physics pre-service teachers to complete a physics concept test. The results showed

\section{Table 1: Middle-school physical phenomena subject: Grade/topics/concepts}

\begin{tabular}{|c|c|c|}
\hline G. & Topics & Concepts \\
\hline \multirow[t]{2}{*}{5} & Friction and measurement of the force & $\begin{array}{l}\text { The magnitude of the force; smooth and rough surfaces; dynamometer; increasing and decreasing } \\
\text { friction }\end{array}$ \\
\hline & Propagation of the light & $\begin{array}{l}\text { Omnidirectional and linear path of the light; regular reflection; diffuse reflection; incident and } \\
\text { reflecting rays; normal of a surface }\end{array}$ \\
\hline \multirow[t]{3}{*}{6} & Force and motion & $\begin{array}{l}\text { Magnitude and direction of the force; resultant force; balanced and unbalanced force; displacement, } \\
\text { velocity, time; constant speed motion }\end{array}$ \\
\hline & Sound and its properties & $\begin{array}{l}\text { Propagation in solids, liquids, and gases; speed of sound; sound energy; reflection of sound; } \\
\text { absorption of sound; sound isolation; acoustics }\end{array}$ \\
\hline & Electrical conduction & Conducting and non-conducting materials; electric resistance; brightness of a bulb \\
\hline \multirow[t]{3}{*}{7} & Force and energy & $\begin{array}{l}\text { Mass, weight, gravity; dynamometer; gravity of celestial bodies; physical work; kinetic energy; types } \\
\text { of potential energy; conservation of energy; friction; air and water resistance }\end{array}$ \\
\hline & Interaction of light and matter & $\begin{array}{l}\text { Absorption of light; colors of objects; solar energy; flat, concave and convex mirrors; refraction of } \\
\text { light; types of lenses; focal point }\end{array}$ \\
\hline & Electric circuits & Electric circuits; series and parallel connection; electrical current; voltage \\
\hline \multirow[t]{3}{*}{8} & Pressure & Solid and liquid pressure; pascal principal \\
\hline & Simple machines & Fixed, moving and block pulleys; lever; incline ramp; wheel and axle; screws \\
\hline & Electric charge and electric energy & $\begin{array}{l}\text { Push and pull forces of electric charges; types of charging; neutral, positive and negative charged } \\
\text { objects; electroscope earthing (static grounding); transformation of energy; transformation to heat, } \\
\text { light, and motion; power plants (hydroelectric, wind, geothermic, and nuclear) }\end{array}$ \\
\hline
\end{tabular}


that those pre-service teachers had serious misconceptions about inertia, gravity, gravitational acceleration, gravitational force, and weight concepts, despite having positive attitudes with regard to a physics lesson.

Finally, Pejuan et al. (2012) explored how 40 engineering students understood the concept of "sound." Their results showed that their participants possessed many misconceptions and inconsistencies on this subject. One of the most common misconceptions was that the sound was propagated by the traveling of air particles, even in solids.

\section{METHODS}

To analyze the pre-service teachers' physics materials, this study used the content analysis technique from qualitative analysis methods. Content analysis is used to analyze verbal, written or visual data by constructing categories about the topic of the research (Silverman, 2006). This study included 27 third grade pre-service science teachers from a public university in Turkey. The study's data were student teachers' lesson plans, materials, photographs of and notes about the materials collected in educational technologies and material design course, which is a compulsory course in all Turkish science curriculums. In the $1^{\text {st }}$ week of the course, instructors assigned a science course topic for each pre-service teacher attending the course. Their objectives were to present a lesson plan together with a teaching material at the deadline, which was the $6^{\text {th }}$ week of the course. The material had to be about their science course topic, had to support learning as a hands-on resource, and had to be designed by pre-service teachers. This objective was only a part of the course. Participants presented their lesson plans and teaching materials to the class together with their lesson plans about their materials at the $6^{\text {th }}$ week. In each presentation, teaching materials were photographed, and notes were taken by the researchers. There were a total of 27 materials and lesson plans about physics phenomena which were given above as the middle school physics content. The materials were discussed by the authors who also administered the material design course.

\section{FINDINGS}

The findings are given under the titles of energy, light, sound, and electricity.

\section{Findings About Energy}

In this section, the title "energy" represents an integrated field for friction and measurement of the force, force and motion, force and energy, pressure, and simple machines topics. Seven lesson plans and materials were presented by the pre-service teachers about energy.

The materials included ramps and cars, which were used to teach friction, kinetic and potential energy, conservation of energy, and velocity. The ramps representing three different types of roads, which were made of plain and frictional floors. Two of the ramps were inclined ramps, while the other one was not. The purpose of this horizontal ramp was to foster students try a toy car over the roads and express their feelings about how fast the car went on each type of floor. Feelings about going fast in this situation are related to the experimenter's decision independent of the type of the road as the experimenter could move the toy car in any speed. A better question should have been about the difficulty to move the car over each type of road instead of the speed of the car. Other two ramps were inclined ramps, where the experimenters had the opportunity to test how far cars go with their potential energy going down on different types of roads. One of the ramp materials is shown in Figure 1.

Another material concerned constant speed motion, which included a cardboard material of two tables (distance-time/ $\mathrm{x}-\mathrm{t}$ and velocity-time/v-t), as well as their graphics. The exact representation of velocity-time table and its graphic in the material is shown in Figure 2.

Although there might not seem a problem, it can be noticed that the table and the graph are not coherent. In the second column of the table, at the starting point ( 0$)$, velocity was given as "zero." On the other hand, in the graph, at the starting point (0), velocity is $60 \mathrm{~km} / \mathrm{h}$. This material leads reviewers to a conclusion that either the vehicle was accelerating in the first stage or the velocity in the second column is given wrong. As constant speed motion is the topic, it is highly probable that the table was wrong. The lesson plan and presentation notes were checked to find out if this was made on purpose, but there was not any information given.

One material presented by a pre-service teacher was about mass and weight. In this material, the designer presents an equal

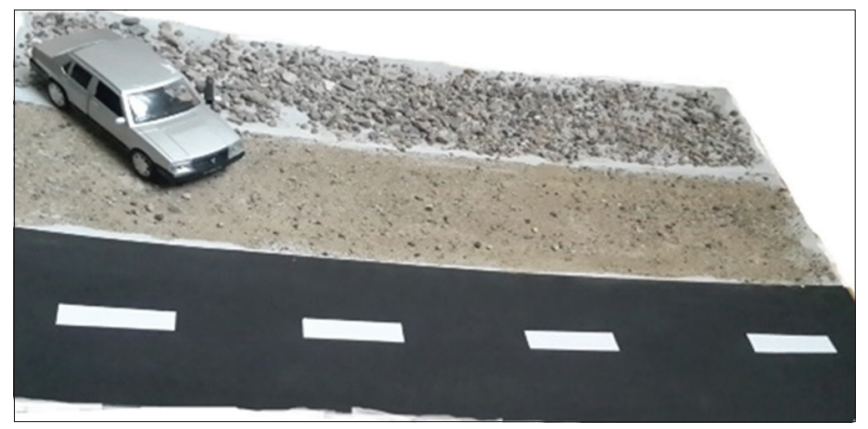

Figure 1: Inclined ramp

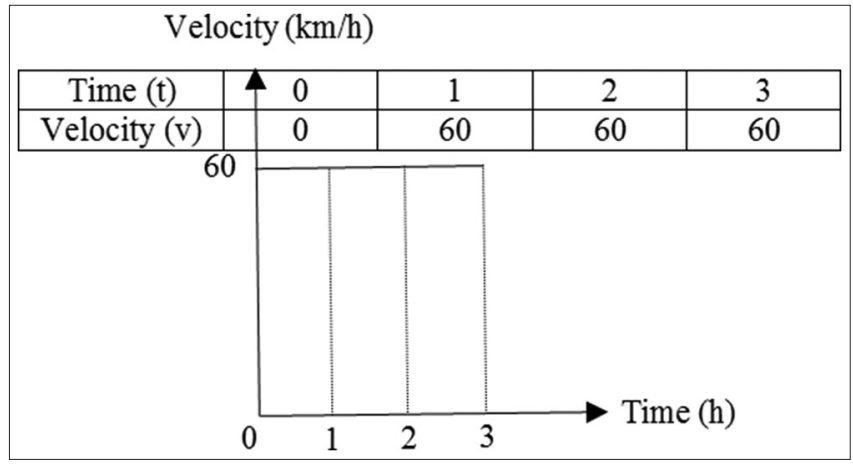

Figure 2: Velocity-time table and graph in the material 
arm scale and a dynamometer to participants, asking them to find out the difference between mass and weight. First, this is more like an activity, not a material. Second, it is a confusing request to ask middle school students to distinguish mass and weight with the given materials. Such topic is quite dependent on the units written on the material, which, in fact, is prone to lead to a misconception.

One material was about potential and kinetic energy, where a ball was placed on top, and a propeller was placed at the bottom on vertical cardboard. The purpose is to push the ball and observe the propeller rotate when the ball hits one of the wings. Regardless of the fact that it is possible for this material to be used to teach the respective topic, not only it looks quite ordinary but also it is not in the level of $7^{\text {th }}$ grade.

The last material for energy was about liquid and solid pressure. The designer of the material had given the name "pressure house" for it. In the vertical part of the material, there are two cylinders and in the horizontal part, there are two plastic bottles. To teach about solid pressure, teachers ask the participators to drop different weighted objects in each cylinder. The bottom side of the cylinders is covered with an elastic material. As a result, the objects in the cylinders push the elastic material in different lengths. To teach about liquid pressure, the bottles in the horizontal part are filled with water, and the cap is closed. Both of the plastic bottles have one pinhole over them in different heights. When the participator loosens the cap, sees the water come out to different distances depending on the height of the pinhole. This material can be seen in Figure 3.

\section{Findings about Light}

In this section, the title "light" represents an integrated field for the propagation of the light, interaction of the light and matter topics. Six materials, including the respective lesson plans, were available on the title "light."

Two of these materials were about colors. The designers both constructed a cardboard theater, where three small flashlights were placed in the place of audience. When they are turned on, viewers can see that they are made of primary colors blue, yellow, and red and combinations of these colors are reflected on the screen of the cardboard theatre. When all three flashlights are turned on, the light on the screen becomes white. One of these materials had followed up activity where blue, yellow, and red pens are given to participants to find out what happens when primary colors are mixed up on a piece of paper. These activities could be useful in earlier grades. For middle school, since they learn primary and accent colors in pre-school and primary school, it is going to be a loss of time and effort. In addition, there is no objective about these materials in the science program. The topic "Interaction of light and matter" includes higher level issues such as absorption of light; colors of objects; solar energy; flat, concave, and convex mirrors; refraction of light; types of lenses; and focal point. Mixing of colors is the easiest part of the topic.
One material was a computer software designed by the designer, which was about mirrors and light rays. In the software, participants can try to reflect light rays on different surfaces and different mirror types. It was a useful and user-friendly material, where the concepts in the topic can be comprehended.

One material was about types of lenses. The designer placed many kinds of plants and flowers in a bowl and glued various kinds of spectacle lenses on the edge of the bowl. The designer asks participants to look at the mini-garden through lenses while asking them to define how different they see through each lens, as well.

One material was about types of mirrors. The designer built a model of a street on cardboard. There is a house, a road, two cars, and a small marketplace. The designer asks experimenters to give examples from daily life. The problem in the material is that it is nearly impossible to find convex and concave mirror examples in this model of the street.

The last material was about the propagation of the light. The designer brought a cardboard box, which has one side open, as well as having some holes on one side. When a light source is placed near the side with the holes, viewers can see the path that light travels. The material can be seen in Figure 4.

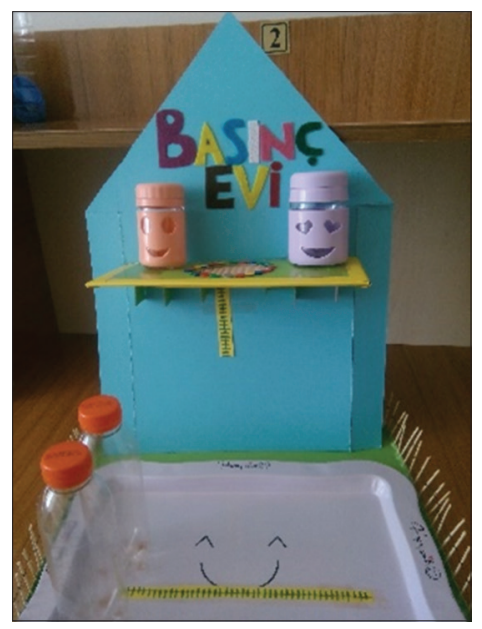

Figure 3: The pressure house

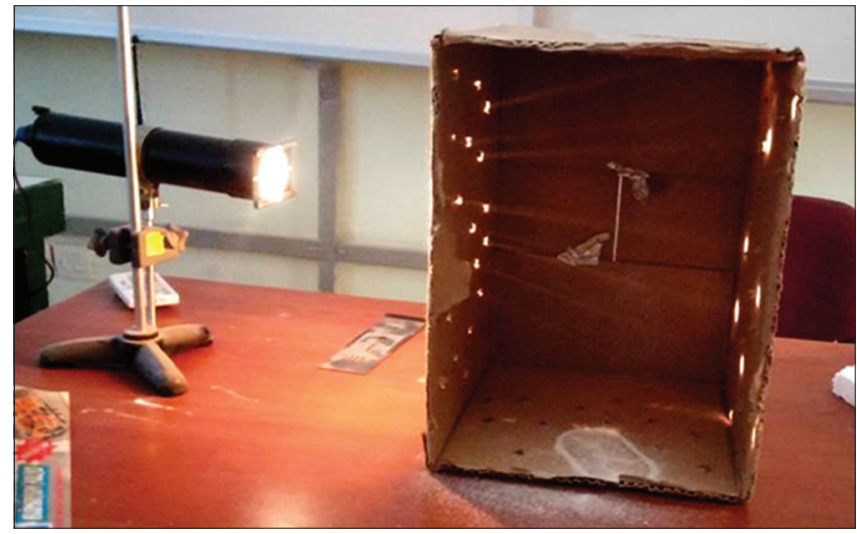

Figure 4: Propagation of light 


\section{Findings about Sound}

In this section, the title "sound" represents an integrated field for sound and its properties topic. Six materials, including the respective lesson plans, were available on the title "sound."

Two of these materials were about producing sound through musical instruments that the designer fabricated. One of them is just a simple drum made of a plastic bucket. Its top was covered with an elastic material, and the designer asks experimenters to hit the top with sticks. It is a way to produce sound, yet the material does not cover any learning outcome of the topic. The other material is a combined product of three different instruments. First one is a drum similar to the previous one, the second one is a shaker, which is a jar half filled with rice, and the third one is a primitive tambourine. Although there is no misconception in making these musical instruments, making and letting students try them does not cope with the learning outcomes of this topic.

One of the materials is about the propagation of sound in solids, liquids, and gases. The designer brought three milk boxes, which are filled with air, water, and sand, respectively. The purpose of this material is to let experimenters place their ears on the boxes, then hit the boxes with a pencil and interpret how sound moves through solids, liquids, and gases.

One of the materials is about sound isolation. The material is a cardboard house, which has an alarm clock inside. The designer provides the students with certain isolation materials such as glass wool and asks them to cover the house properly, while comparing the difference between the covered and uncovered house when the alarm clock is alarming, as well.

Remaining two materials are pressured air generators, which are not really about the sound field. The intention of the pressured air generator is a toy-like mechanism that pressures the air in a cylinder, which has a smaller exit resulting in a straight moving airwave. This kind of toys is named as airzooka. The airwave exiting from the generator can knock down plastic cups. The designers of both air generators brought plastic and carton cups to let students try the mechanism. Although this is an attractive and funny scientific material, it has no connection with the topics in the sound field. The pressured air generators are shown in Figure 5.

\section{Findings about Electricity}

In this section, the title "electricity" represents an integrated field for electrical conduction, electric circuits, electric charge, and electric energy topics. Eight materials, including the respective lesson plans, were available on the title "electricity."

Three of these materials were online-based, which were all about electric circuits. First one was a premade cartoon, which explains serial and parallel electric circuits; the second one was an online circuit making application, in which users can build complex circuits by clicking on cables, light bulbs, and batteries; and the third one was a presentation of a concept mapping application. As there is almost no effort in presenting these as materials, despite having no misconception, they are not suitable for the purpose of this course.
Three materials for electricity were about electric circuits. The first designer built a three floored wooden and cardboard house with a side open for viewers to see inside. In addition, there is an illumination system in the house. When the designer presses a button behind the house, viewers see that some rooms are illuminated, some of them are in the dark. The designer provides some conducting and non-conducting materials such as nails, screws, plastic and wooden objects, ceramic and carbon objects, asking the viewers to find the problems in the illumination system, and make all rooms illuminated with the provided materials. The second designer's material was also about the relationship between resistance and brightness. The material consists of an electric circuit with a homemade rheostat. The designer asked students how brightness would change while switching the rheostat and lets them try. The third designer presented a complex electric circuit, which is made of eight switches, eight different cables, three light bulbs, and a 9v battery. The purpose of this material is to let students discover the relationship between brightness and electric resistance. This material simply looks like a different version of rheostat as the designer choses the cables, which might limit the experimenter. This material is shown in Figure 6.

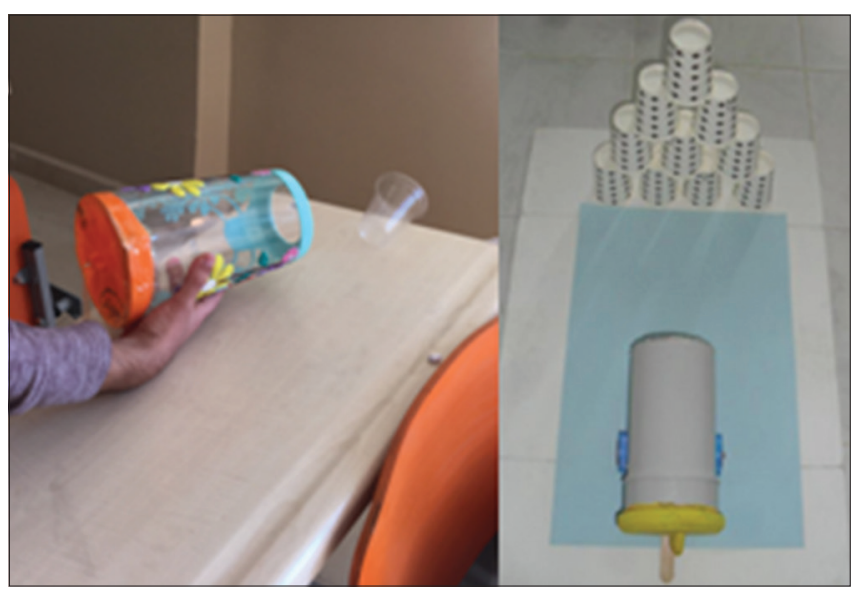

Figure 5: Pressured air generators

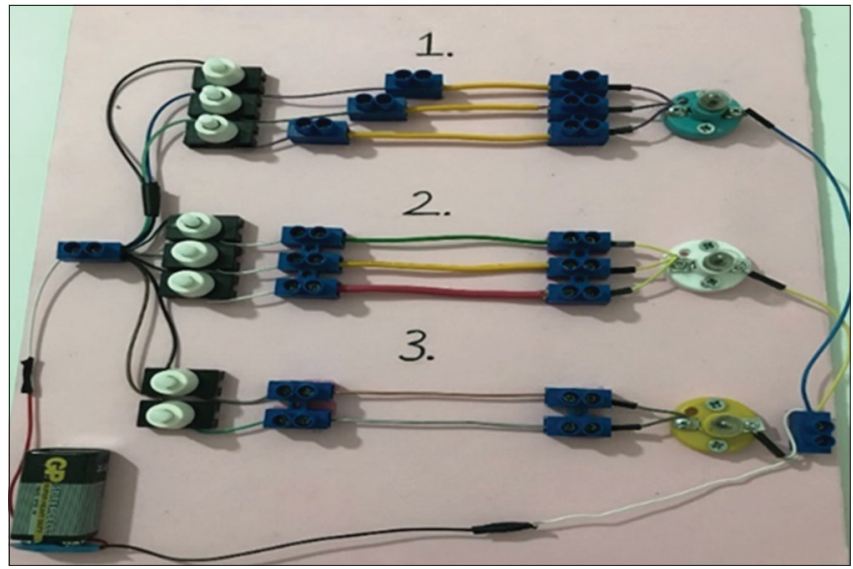

Figure 6: Resistance and brightness material 
One material is a homemade electroscope, which is built in a glass bottle. It is a successful material that would teach $8^{\text {th }}$ grader how to build an electroscope with common and easy to find materials.

The last material was, in fact, not a material, but rather an experiment. The designer brought experiment sets for every group in the class, asking them to construct a simple light bulb. Each set has a beaker, cables, cardboard, glass plate, pencil graphite, electric tape, and power supply. If everything goes well with the experiment, the graphite shines. As mentioned before, despite the effort for preparing the experiment sets, this experimenting process cannot be classified as a material.

\section{Summary of Findings}

There were 27 physics materials presented by pre-service teachers, which consist of the materials on energy (7 materials), light (6 materials), sound (6 materials), and electricity (8 materials). Findings of the materials are summarized in the following articles. The rest of the materials, which are not mentioned below are accepted as successful and acceptable materials.

- $\quad$ Three of seven materials in energy field were identified as either they have misconceptions (constant speed motion) or they have a possibility to cause a misconception (mass and weight), and one material was identified as too simple for the grade level (kinetic and potential energy). The acceptableness rate of the materials presented in this field is $57 \%$.

- One of six materials in the light field was identified as irrelevant (types of mirrors) and two of the six materials were identified as too simple for the grade level (colors). In addition, there is one successful technological material. The acceptableness rate in this field is $50 \%$.

- Two of six materials in the sound field were identified as irrelevant (musical instruments) and two other materials did not belong to sound field (air pressure generators), which might be a clue of possible misconceptions of the designers of these materials. The acceptableness rate in this field is $33 \%$.

- Three of eight materials in the electric field were topicrelevant computer presentations, which were not classified as materials but teaching resources. One of eight materials was an experiment rather than a material (making a light bulb). The acceptableness rate in this field is $50 \%$.

- Identified misconceptions were linked to velocity, mass, and weight, and sound energy concepts.

\section{DISCUSSION AND IMPLICATIONS}

Although the materials investigated in this research are assignments of a university course, the topics and concepts in question are learned in middle school. In other words, the preservice teacher participants of this research had been learning these topics literally, for years. Yet, when it comes to designing a material about the topics, they had been learning for years, plus their five-semesters background in the faculty of education, only 13 of 27 materials were acceptable by the instructors of the course. Unexpectedly but gladly, only three of the materials were linked to a misconception. This is contrary to the related literature where pre-service teachers possessed high rates of misconceptions (e.g., Narjaikaew, 2013; Pejuan et al., 2012; Stein et al., 2008; Gönen, 2008; Kikas, 2004; Crawley and Arditzoglou, 1988). Another unexpected finding in this research was the unwillingness of the participant pre-service teachers. Besides small number of misconceptions, most of the participants chose to design either too simple, easy to build, easy to find, digital, or irrelevant materials. Where a material is simple, the possibility of possessing a misconception in it might be lower. This could be the reason for the low misconception rate in this study.

As mentioned in the previous paragraph, the unwillingness of the pre-service teachers is a major issue identified in this study. Turkish science education program is based on a constructivist approach, and student-centered teacher-guided STEM activities are recommended in all science courses. Although participants had enough knowledge about scientific topics and enough time for the material design process, they did not pay enough attention and they did not show their best. Unwillingness was the overall image of the participants. Considering the constructivist and STEM-based nature of the science program, unwillingness is an undesired output.

The misconceptions identified in this study were linked to velocity, mass, and weight, and sound energy concepts. Force and velocity topics are often considered as the most difficult topics (Kikas, 2004), and conceptual understanding of these concepts is usually low (Narjaikaew, 2013). It would be expectable to detect a misconception about velocity while carrying out misconception research. Likewise, mass and weight are commonly encountered concepts, which can be found in misconception studies (e.g., Gönen, 2008). Sound is another abstract concept, which can also be encountered in misconception studies (e.g., Pejuan et al., 2012). Teachers should be well equipped with scientific and abstract concepts knowledge to manage the qualitative discussions, which are critical for learning with understanding (Kikas, 2004). In a regular pre-service teachers' training process, it is very difficult to detect the misconceptions that they hold. If the pre-service teachers graduate with such misconceptions, it will be even more challenging to settle them. As a result, most of them will be transferred to the students.

Determining misconceptions of pre-service teachers is a solution to come up with a remedy for their misconceptions. However, there would not be enough time to detect every misconception pre-service teachers hold. Instead, teaching them about misconceptions in science education courses and recommending readings of misconception studies, as well as making them aware of the most common misconceptions would be a better solution. In addition, the findings of this study revealed the need of a new term, unwillingness, which has not been defined in education studies before. 
Burgoon (1976) connected the term unwillingness with communication, apprehension, low self-esteem, lack of communicative competence, anomie, alienation, and introversion. There are other studies including risk-taking, class sociability, anxiety (Liu and Jackson, 2008), and shyness (Kelly, 1981) concepts. Apart from these, in an educational perspective, unwillingness probably has a correlation with motivation, attitudes, and beliefs toward science, teaching, or science teaching, in particular. For further investigation, studies examining the aforementioned concepts, their relationships, and in-depth qualitative analysis to reveal the causes of unwillingness would be quite efficient for researchers.

\section{REFERENCES}

Akgun, A., Gonen, S., \& Yilmaz, A. (2005). Misconceptions of preservice science teachers regarding the structure and conductivity of mixtures. Hacettepe University Journal of Education, 28, 1-8.

Burgoon, J.K. (1976). The unwillingness to communicate scale: Development and validation. Communications Monographs, 43(1), 60-69.

Crawley, F.E., \& Arditzoglou, S.Y. (1988). Life and Physical Science Misconceptions of Preservice Elementary Teachers. Paper presented at the Annual Meeting of the School Science and Mathematics Association.

Deslauriers, L., Schelew, E., \& Wieman, C. (2011). Improved learning in a large-enrollment physics class. Science, 332(6031), 862-864.

Gönen, S. (2008). A study on student teachers' misconceptions and scientifically acceptable conceptions about mass and gravity. Journal of Science Education and Technology, 17(1), 70-81.

Häussler, P., \& Hoffmann, L. (2000). A curricular frame for physics education: Development, comparison with students' interests, and impact on students' achievement and self concept. Science Education, 84(6), 689-705

Kelly, L. (1981). A rose by any other name is still a rose: A comparative analysis of reticence, communication apprehension, unwillingness to communicate, and shyness. Human Communication Research, $8(2), 99-113$.

Kikas, E. (2004). Teachers' conceptions and misconceptions concerning three natural phenomena. Journal of Research in Science Teaching, 41(5), 432-448.

Knight, R. (2004). Five Easy Lessons: Strategies for Successful Physics Teaching. San Francisco, CA: Pearson.

Lawrenz, F. (1986). Misconceptions of physical science concepts among elementary school teachers. School Science and Mathematics, 86(8), 654-660.

Liu, M., \& Jackson, J. (2008). An exploration of Chinese EFL learners' unwillingness to communicate and foreign language anxiety. The Modern Language Journal, 92(1), 71-86.

Martin, D.J. (2012). Elementary science methods: A constructivist approach. Boston, MA: Cengage Learning.

McDermott, L.C., Shaffer, P.S., \& Constantinou, C.P. (2000). Preparing teachers to teach physics and physical science by inquiry. Physics Education, 35(6), 411.

Ministry of National Education (MoNE). (2018). Science Education Curriculum (Primary and Middle School 3., 4., 5., 6., 7., $8^{\text {th }}$ Grades). Ankara, Turkey: Ministry of National Education.

Narjaikaew, P. (2013). Alternative conceptions of primary school teachers of science about force and motion. Procedia-Social and Behavioral Sciences, 88, 250-257.

Pejuan, A., Bohigas, X., Jaén, X., \& Periago, C. (2012). Misconceptions about sound among engineering students. Journal of Science Education and Technology, 21(6), 669-685.

Silverman, D. (2006). Interpreting Qualitative Data: Methods for Analysing Talk, Text and Interaction. $3^{\text {rd }}$ ed. London: SAGE.

Stein, M., Larrabee, T.G., \& Barman, C.R. (2008). A study of common beliefs and misconceptions in physical science. Journal of Elementary Science Education, 20(2), 1-11.

Tiberghien, A., Jossem, E.L., \& Barojas, J. (1998). Connecting Research in Physics Education with Teacher Education. International Commission on Physics Education. Available from: http://www.kdfls1.troja.mff.cuni. cz/publications/teach1/ConnectingResInPhysEducWithTeacherEduc_ Vol 1.pdf. [Last accessed on 2018 Dec 18].

Weaver, A.D. (1965). Misconceptions in physics prevalent in science textbook series for elementary schools. School Science and Mathematics, 65(3), 231-240.

Yagbasan, R., \& Gülcicek, A.G.C. (2003). Describing the characteristics of misconceptions in science teaching. Pamukkale University Journal of Education, 13(13), 102-120. 